\title{
Vulnerable People in Microscopic Evacuation Modelling
}

\author{
Rainer Könnecke ${ }^{1}$, Volker Schneider ${ }^{2}$ \\ ${ }_{1,2}$ IST GmbH \\ Feuerbachstraße 19, 60325 Frankfurt, Germany \\ r.koennecke@ist-net.de; v.schneider@ist-net.de
}

\begin{abstract}
Computational evacuation modelling as a part of approval procedures or design processes is sometimes concerned with vulnerable people requiring special attention. This vulnerability can be based on external circumstances or on individual characteristics. Microscopic methods are well suited to deal with such specific determinants by their ability to model individual movement and certain behavioural aspects. By reference to case studies the possibilities of up-to-date individual evacuation models to cover egress scenarios including vulnerable people are discussed. The selected examples demonstrate that the evacuation of vulnerable people often depends more on the modelling of individual behaviour rather than on a very detailed description of individual characteristics. Group formation and the guidance or assistance of other people will have a strong impact on the evacuation process and thus require special modelling techniques and respective calibration and validation efforts guided by empirical studies.
\end{abstract}

Keywords: mobility restrictions, microscopic modelling, vulnerable people, egress movement, guided evacuation

\section{Introduction}

Computational evacuation modelling as a part of approval procedures or design processes is sometimes concerned with vulnerable people requiring special attention. This vulnerability can be based on external circumstances, as in the first sample case, or on individual characteristics as presented in the second example. Both case studies include numerical simulations with the microscopic evacuation model ASERI [1] and [2]. For the second example, the results of the numerical simulations can be compared to corresponding empirical data.

\section{Train Evacuation inside a Tunnel}

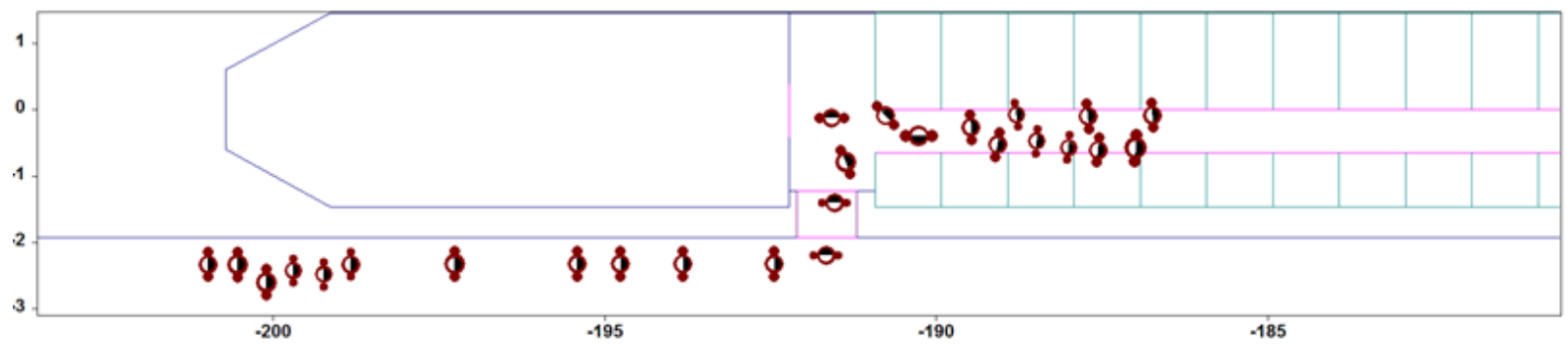

Fig. 1: Snapshots from an ASERI simulation for train evacuation inside a tunnel

This sample application of egress from a train refers to an unscheduled stop within a tunnel, requiring controlled evacuation of the coaches. The evacuation concept requires that only certain specified exits of the coaches are used for egress. Further limitations or prioritizations are posed by the cause of the evacuation, e.g. a fire inside a coach. The goal of such an egress study is the optimization of the details of 
the evacuation procedure. Conductors are present at the coach exits to assist the evacuees. Furthermore, conductors will guide the passengers within the train to the available exits, thus establishing a controlled evacuation. A possible evacuation concept is based on a phased evacuation coach by coach. The passengers within one coach are guided by a conductor to the appropriate exit, while the other passengers are waiting until it is their turn to start egress guided by a conductor. The special features covered by the ASERI evacuation model are the phased evacuation of groups of passengers within the narrowness of the coaches and the process of exiting the coach inside a tunnel. The latter requires the negotiation of a considerable height from exit level to the tunnel surface. This requires empirical data to establish the order of magnitude of the exit flow and a sensitivity analysis to cover the uncertainties of the sparse empirical data available. Figure 1 shows a detail from such a train egress simulation.

\section{School Evacuation including Wheelchair Users}

Evacuation exercises performed at a German academic high school with focus on the vertical assisted movement of wheelchair users were investigated in [3]. Two scenarios were monitored: scenario 1 (reference scenario) consists of 49 pupils and 3 teachers without mobility restrictions, scenario 2 includes in addition two wheelchair users.

The exercises involved one staircase of the school connecting three classrooms from the upper storey to the foyer at ground level. The stair has two intermediate landings. There are two larger stairs (12 steps each) and one small stair to the foyer (4 steps). Step width is $29,5 \mathrm{~cm}$, step height $17 \mathrm{~cm}$. Stair width is $1,61 \mathrm{~m}$ with handrails reducing the width to $1,46 \mathrm{~m}$.

Three exercises were performed for scenario 1 and four exercises for scenario 2 . It was therefore not an unannounced evacuation drill. The occupants of the three classrooms were alarmed at the same time by portable radiophones. They were instructed to leave behind all bags and similar items and to egress at normal pace. The pupils that assisted the wheelchair users were not assigned in advance and thus were different for the individual exercises of scenario 2.

Table 1: Egress time for the evacuation exercises

\begin{tabular}{|r|c|c|c|c|}
\hline scenario & exercise 1 & exercise 2 & exercise 3 & exercise 4 \\
\hline 1 & $79 \mathrm{~s}$ & $73 \mathrm{~s}$ & $74 \mathrm{~s}$ & \\
\hline 2 & $94 \mathrm{~s}$ & $120 \mathrm{~s}$ & $123 \mathrm{~s}$ & $118 \mathrm{~s}$ \\
\hline
\end{tabular}

Table 1 lists the evacuation times from starting signal until the last pupil has reached the foyer. For scenario 1, a smooth flow was observed on the stairs (figure 2), resulting in egress times for the three exercises very close to each other. For scenario 2, there is a substantial difference between exercise 1 and the other three exercises. The shorter egress time of $94 \mathrm{~s}$ is explained by the fact, that in exercise 1 the wheelchairs were carried straight downstairs without any pausing on the landings. Whereas in the other exercises the wheelchairs were dropped on the landings and pushed to the next flight of stairs. In most cases ( 7 from 8 ) the wheelchairs were transported by three assistants - two in front and one behind (figure 3). In one case, four assistants did transport the wheelchair downstairs. In all exercises the wheelchair users left the classroom prior to the other pupils. The further movement of the wheelchair users did vary in the four exercises. In exercise 2-1, one wheelchair was transported first, then the main flow of pupils and the second wheelchair last. In the other three exercises both wheelchairs were transported after the main flow of pupils. For these cases the wheelchair users took waiting positions in the upper floor outside the classrooms.

Scenario 1 and 2 were also simulated using the microscopic evacuation model ASERI with its feature to model independent movement of wheelchair users and assisted vertical transport of wheelchairs [2]. The size of the wheelchairs had been derived from the actual wheelchair sizes used in the exercises. The results for scenario 1 (no reaction time) vary between $76 \mathrm{~s}$ and $81 \mathrm{~s}$ (10 runs), with smooth flow on the stairs as observed during the exercises. For scenario 2, the egress time varies between $94 \mathrm{~s}$ and $105 \mathrm{~s}$ (19 runs). The simulations for scenario two did not include explicit waiting positions for the wheelchair users and are thus representative for exercise 2-1. The 
wheelchair users in the numerical simulation move towards the tread of stairs and are then immediately assisted by two helpers at the side of the wheelchair to assist vertical transport.

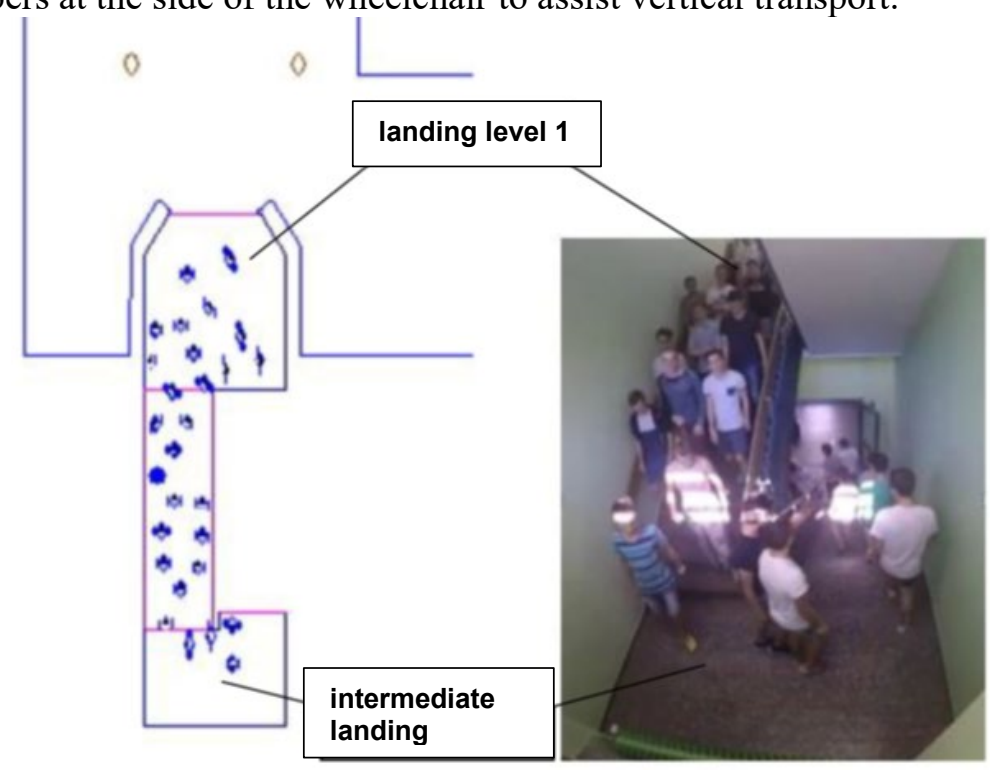

Fig. 2: Snapshots from exercise 1-3 (right) and corresponding ASERI simulation (left) - @ J. Melles [3]

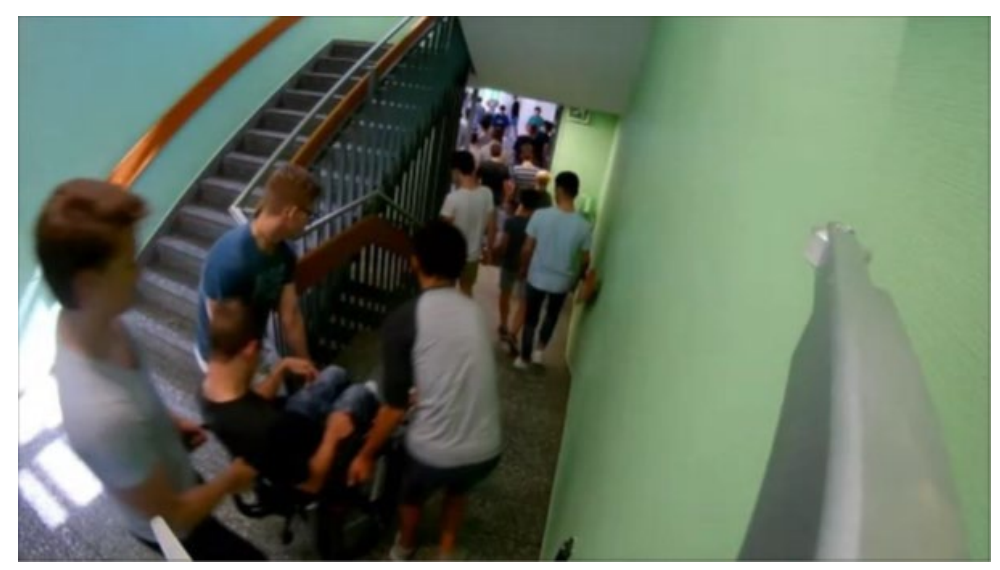

Fig. 3: Snapshot from exercise 2-3 - (C) J. Melles [3]

\section{Conclusion}

It is demonstrated that microscopic methods are well suited to deal with egress modelling of scenarios including vulnerable people. Example 1 shows the capability of the ASERI evacuation model to describe highly organized phased evacuation in constricted surroundings. The empirical data presented in the second case can be matched very well with the corresponding calculations.

Additional empirical data, including an evacuation drill in a large office building with vertical evacuation of wheelchair users with the help of evacuation chairs, will be used for further validation of the ASERI evacuation model with respect to the modelling of heterogeneous groups.

\section{Acknowledgements}

The authors wish to thank Julian Melles (IfB Ingenieurgesellschaft für Brandschutz mbH Bad Kreuznach) for his permission to include parts from his master thesis in this paper.

\section{References}


[1] V. Schneider, "Application of the individual-based evacuation model ASERI in designing safety concepts" in Proceedings of the 2nd Int. Symp. on Human Behaviour in Fire, Boston, March 2001.

[2] V. Schneider and R. Könnecke, "Occupants with mobility impairments and social groups in design calculations" in 6th Int. Symp. on Human Behaviour in Fire, Cambridge, September 2015.

[3] J. Melles, "Datenerfassung für die Entfluchtungssimulation für mobilitätseingeschränkte Personen mittels Ingenieurmethoden im Brandschutz," Master Thesis Hochschule Darmstadt, 29.09.2017. 